\title{
Erratum to: Development and validation of the functional assessment of chronic illness therapy treatment satisfaction (FACIT TS) measures
}

\author{
John D. Peipert · Jennifer L. Beaumont • \\ Rita Bode $\cdot$ Dave Cella $\cdot$ Sofia F. Garcia $\cdot$ \\ Elizabeth A. Hahn
}

Published online: 15 February 2014

(c) Springer International Publishing Switzerland 2014

\section{Erratum to: Qual Life Res \\ DOI 10.1007/s11136-013-0520-8}

In the original publication of the article, a funding support has been missed in the acknowledgement section. The complete acknowledgement is given below.

Acknowledgments Funding for this project was provided by Grants from the Drug Information Association, the National Cancer Institute
(R01-CA060068 and R01-CA115361), and the Evanston Northwestern Healthcare Breast and Ovarian Research Program (EH06-225). The authors thank all the patients and clinical/research experts who participated in this project. The authors also thank Susan Yount, Ph.D., for her contribution of data from the SyMon-L project. A portion of Dr. Garcia's time toward this publication was supported by the National Center for Complementary and Alternative Medicine and the National Institute of Arthritis and Musculoskeletal and Skin Diseases of the National Institutes of Health under award number U54AR057951-S1.

The online version of the original article can be found under doi:10.1007/s11136-013-0520-8.

\footnotetext{
J. D. Peipert

Division of General Medical Sciences, Washington University School of Medicine, 660 S. Euclid Ave., Campus Box 8005, St. Louis, MO 63110, USA

J. D. Peipert · J. L. Beaumont - R. Bode $\cdot$ D. Cella ·

S. F. Garcia · E. A. Hahn $(\square)$

Department of Medical Social Sciences, Feinberg School of

Medicine, Northwestern University, 633 N. St. Clair St.,

Suite 1900, Chicago, IL 60611, USA

e-mail: e-hahn@northwestern.edu
} 